\title{
APLIKASI PENCEGAH PLAGIASI JUDUL TUGAS AKHIR DI AMIK TRI DHARMA PEKANBARU BERBASIS WEB
}

\author{
Suwarti \\ AMIK TRI DHARMA PEKANBARU \\ Jl. Jend. Sudirman No. 68 D, Pelita Pantai, Pekanbaru, 28151 \\ Suwarty.atd87@gmail.com
}

\begin{abstract}
ABSTRAK
AMIK “Tri Dharma Pekanbaru merupakan salah satu kampus yang mulai berkembang, fasilitas yang mulai lengkap akan tetapi masih memiliki kelemahan yang cukup kompleks dalam mlakukan pengajuan judul tugas akhir. Terutama dalam mencari judul yang tidak mirip dengan terdahulu. Sampai saat ini AMIK Tri Dharma Pekanbaru dalam melakukan pengajuan judul tugas akhir mahasiswa masih menggunakan sistem secara manual, dengan cara mahasiswa memberi judul tugas akhir dengan tulisan kepada prodi. Sehingga judul yang diajukan mahasiswa sering sekali ditolak dikarenakan adanya kemiripan dengan judul terdahulu atau kurang efisien. Oleh karena itu dengan adanya aplikasi pencegah plagiasi judul tugas akhir berbasis web ini merupakan salah satu mempermudah mahasiswa dalam melakukan pengajuan judul tugas akhir. Judul tugas akhir ini diimplementasikan menggunakan bahasa pemrograman PHP sedangkan untuk pengolahan databasenya menggunakan MySQL.
\end{abstract}

Kata Kunci : Tugas Akhir, Plagiat, Php, MySQL, Website.

\begin{abstract}
AMIK “Tri Dharma Pekanbaru is one of the campuses that are starting to develop, the facilities are starting to be complete but still have quite complex weaknesses in submitting the title of the final project. Especially in looking for titles that are not similar to the previous one. Until now, AMIK Tri Dharma Pekanbaru in submitting student final project titles is still using the system manually, by way of students giving the title of their final project in writing to the study program. So that the title submitted by students is often rejected because of the similarity with the previous title or inefficient. Therefore, the existence of this web-based plagiarism prevention application is one way to make it easier for students to submit final assignment titles. The title of this final project is implemented using the PHP programming language while for database processing using MySQL.
\end{abstract}

Keywords: Final Project, Plagiarism, Php, MySQL, Website.

\section{PENDAHULUAN}

Praktik plagiasi tidaklah menjadi hal asing lagi, apalagi dikalangan mahasiswa sekarang yang hampir setiap hari mengerjakan tugas yang diberikan oleh dosen tak terkecuali pula, mahasiswa Amik Tri Dharma sering mendapat tugas untuk membuat program aplikasi dengan menggunakan bahasa pemrograman tertentu. Dalam pengerjaan tugas tersebut, praktik plagiasi tak terelakan lagi untuk dilakukan mengingat waktu pengerjaannya tugas yang terbatas dan tidak adanya motivasi untuk berusaha menyelesaikan tugas dengan kemampuan sendiri. Praktik plagiasi dilakukan dengan cara tukar-menukar kode program (source code) yang telah berhasil. Mahasiswa yang memplagiasi dapat dengan mudah menyalin atau mengganti kode program yang telah didapatkan secara cepat dengan menggunakan fitur-fitur yang disediakan komputer. Untuk mengatasi praktik plagiasi tidaklah cukup hanya mengingatkan kepada mahasiswa bahwa, tindakan plagiasi tidaklah baik dilakukan. Pendeteksian praktik plagiasi merupakan solusi yang sebaiknya dilakukan. Sehingga tindakan curang tersebut dapat diminimalissasi.

Dalam mencegah plagiasi judul tugas akhir, pihak Amik tri dharma masih 
INFORM TIK A

Jurnal Informatika, Manajemen dan Komputer, Vol. 13 No.1, Mei 2021

eISSN : 2580-3042

pISSN : 1979-0694

menggunakan sistem manual dalam pengecekannya. Dengan adanya program aplikasi pencegah plagiasi judul tugas akhir menggunakan website, mahasiswa setiap pengajuan judul tahunnya dapat mengecek secara lebih mudah, apakah judul sudah ada yang mengajukan atau belum misalnya, mahasiswa tiap tahunnya selalu mengajukan judul tugas akhir kepada dosen, dan dosen menolak karena sudah ada judul tersebut, jadi untuk mengatasi hal tersebut kita bisa melihat dari website tentang judul yang sudah ada. Akibat dari plagiasi ini adalah mahasiswa dapat menjiplak karangan ilmiah orang lain atau judul yang sudah ada.

Setelah dilakukan pengamatan pada sistem yang berjalan di Amik tri dharma, dapat diketahui bahwa kendala dan masalah yang ada yaitu, terjadinya kesalahan mahasiswa sering menjatuhkan judul yang sudah ada, sehingga tidak terima oleh pihak pembimbing. Melihat hal tersebut maka perlunya dibuat sistem pencegah plagiasi berbasis website, agar mempermudah mahasiswa melihat judul yang sudah ada tiap tahunnnya.

Pada peneitian sebelumnya dikatakan bahwa masalah-masalah pengelolaan skripsi mahasiswa biasanya diselesaikan dengan membangun sebuah sistem online yang dapat digunakan mahasiswa untuk mendaftar skripsi, mencari referensi skripsi sebelumnya, mencari topik skripsi dan lainnya. Sedangkan dari sisi fakultas proses pengelolaan skripsi secara online dapat mengurangi pekerjaan karyawan pada saat pendataan skripsi dimana mahasiswa dapat membantu menginput data skripsi. Dan bukan karyawan sendiri yang mengetikan data-data skripsi mahasiswa. Selain itu memudahkan bagi fakultas dalam proses pengarsipan dan lainnya. Oleh karena itu sistem pengelolaan skripsi perlu dilengkapi berbagai macam fitur tambahan yang dapat berguna bagi seluruh pihak (Yamasari, Asmunin, \& Kurniawan, 2015).

Plagiarisme dalam penulisan karangan ilmiah saat ini sangat mudah dilakukan. Untuk mengatasinya, setiap karya ilmiah tersebut perlu diperiksa apakah hasil plagiarisme atau bukan dengan memeriksa setiap jengkal teks yang ada. Sistem ini dibangun dengan mengimplementasikan algoritma Rabin-Karp. Untuk mendeteksi adanya kemiripan, dua teks dibandingkan dengan mentransformasikan ke dalam bentuk deretan angka yang mengacu pada tabel ASCII, disebut juga dengan proses hashing.

Algoritma ini dikombinasikan dengan metode Synonym Recognition sehingga dapat menemukan kata-kata yang benar-benar sama atau kata yang sudah dirubah kebentuk kata yang bermakna sama. (P. Pratama, Afriansyah, \& Syaifullah, 2019).

Plagiarisme adalah suatu tindakan yang sangat tidak patut dan tergolong sebagai bentuk penipuan dan pemalsuan yang melanggar etika pendidikan. Selain plagiarisme yang merupakan pelanggaran berat, budaya instan pendidikan yang lebih mengutamakan kemudahan dibandingkan dengan proses, nilai moral serta etika juga mendorong munculnya perilaku untuk mendapatkan hasil cepat tanpa mau belajar lebih dulu.Termasuk dalam hal ini adalah penguasaan keterampilan yang bersifat teknis. (Z. Pratama, Utami, \& Arief, 2019).

Dampak.akses informasi yang mudah membuat tindakan plagiasi makin marak. Tindakan tersebut dapat dicegah dengan menggunakan sistem deteksi plagiat. Sistem tersebut dapat dibangun dengan menggunakan konsep similarity dengan algoritma rabin-karp sebagai string matchingnya dan $\mathrm{n}$-gram sebagai metode parsingnya. Tujuan pada penelitian ini adalah membandingkan metode parsing untuk mengetahui metode parsing yang mana yang dapat memberikan hasil paling cepat dan masih dalam nilai akurasi yang wajar. sebagai kontrol ukuran akurasi menggunakan plagiarism checker $\mathrm{x}$ free. Aplikasi tersebut untuk menentukan akurasi instrumen pengujian menggunakan selisih similarity. Hasilnya adalah menemukan fakta jika ngram word memiliki akurasi yang paling optimal dibanding n-gram yang lain dan masih relative paling cepat dibanding lainnya. (Putra \& Sularno, 2019).

Plagiarisme adalah sebuah masalah yang cukup signifikan pada banyak bidang termasuk universitas. plagiarisme yang biasanya dilakukan terhadap konten digital adalah melakukan copypaste terhadap dokumen asli. Untuk mengantisipasinya, dibutuhkan suatu cara yang dapat menganalisis Teknik plagiarisme. Ada beberapa pendekatan yang bisa diambil, contohnya dengan mempergunakan algoritma pencarian string Rabin-Karp karena algoritma ini dapat digunakan untuk mendeteksi plagiarisme pada sebuah dokumen teks. Pada tahap pengujian, dokumen uji yang digunakan berjumlah tiga dokumen dengan kategori tingkat kemiripan rendah, sedang dan tinggi. Dari beberapa pengujian yang telah dilakukan, pendekatan ini dapat menemukan kutipan terpanjang yang sama di antara dua dokumen teks 
INFORM T IKA

Jurnal Informatika, Manajemen dan Komputer, Vol. 13 No.1, Mei 2021

eISSN : 2580-3042

pISSN : 1979-0694

serta mengukur kemiripan dokumen teks. Dengan sistem ini akan membantu mencegah aksi plagiarism pada pendaftaran proposal skripsi sehingga tidak adanya skripsi yang sama. (Sari, 2019).

Salah satu tantangan dalam bidang akademik adalah mencegah maraknya aktivitas plagiarisme. Salah satu cara yang bisa dilakukan adalah dengan melakukan deteksi dini plagiasi terhadap karya mahasiswa terutama skripsi. Penerapan deteksi indikasi plagiarisme menggunakan metode n-grams dan winnowing merupakan tujuan dari penelitian ini, dan menemukan nominal $n$ yang efektif. Kata yang ada dalam

dokumen skripsi direpresentasikan dalam bentuk hash, lalu dilakukan seleksi menggunakan algoritma winnowing untuk menentukan fingerprint dari dokumen yang akan disimpan dalam basis data. Pengujian dilakukan dengan menggunakan sampel dokumen skripsi mahasiswa. Hasil akhir dari penelitian tersebut menunjukkan bahwa sistem dapat mendeteksi adanya plagiasi menurut kesamaan kata secara konsisten berdasarkan beberapa skenario pengujian yang dijalankan, nominsl $n$ yang paling efektif dalam deteksi kesamaan kata yaitu $n=7$ dengan prosentase $3,07 \%$ berdasarkan selisih antara pengujian menggunakan sistem dan pengujian manual. (Sibarani, Magdalena, \& Dharma, 2019).

Dalam penelitian lain mengatakan bahwa untuk mengetahui persepsi mahasiswa akuntansi pada PT deteksi plagiarisme dalam penulisan tugas akhir / tesis. Total populasi ini studi adalah 100 mahasiswa akuntansi yang sedang mempersiapkan tugas akhir / tesis mereka. Hasilnya menunjukkan bahwa sebagian besar mahasiswa akuntansi dalam tugas akhir masih melakukan plagiarisme karena berbagai alasan. Untuk menghindari plagiarisme oleh siswa, yang menyediakan pemahaman kepada mahasiswa tentang arti plagiarisme dari dosen dan mata kuliah terkait institusi (Waly, 2018).

Dalam Perguruan Tinggi salah satu kewajiban yang harus dilakukan adalah penyelesaian tugas akhir yaitu skripsi. Sebagian besar mahasiswa saat ini banyak yang melakukan kecurangan atau pun cara yang tidak efektif dalam menyelesaikan skripsinya, salah satu yang sering dilakukan adalah copypaste dari skripsi atau jurnal yang sudah ada sebelumnya atau bisa disebut plagiarisme. Tindakan plagiarisme atau penjiplakan ini dilakukan dengan cara yang sangat mudah yaitu mereka yang dapat mengganti sebagian

kata-kata dengan mengambil sinonim dari artikel tersebut. Solusi yang dapat diberikan untuk mengatasi masalah seperti ini yaitu dengan system pendeteksian kemiripan judul atau pun teks skripsi yang dilakukan dengan menggunakan Algoritma Winnowing dan Algoritma Rabin-Karp. Algoritma winnowing ini digunakan untuk mendeteksi adanya keberadaan kesamaan kata dalam dua buah judul, sedangkan Algoritma Rabin-Karp digunakan untuk melakukan pendeteksian atau pun pencarian untuk string yang berjumlah banyak. Oleh sebab itu dengan adanya aplikasi ini akan sangat membantu dan memudahkan dosen atau pun kaprodi dalam melakukan pengecekan judul skripsi. Pengujian algoritma winnowing dan rabin-karp ini memiliki tingkat akurasi yang sudah mendekati $75 \%$ dan dirancang dapat membandingkan dua judul skripsi. (Wijayanti \& Hariri, 2019).

\section{METODOLOGI PENELITIAN}

Penelitian ini dilakukan dan dapat diselesaikan menggunakan model SDLC yang dipakai dalam penelitian ini adalah model Waterfall. Waterfall Model atau Classic Life Cicle merupakan model yang paling banya dipakai dalam Software Enginnering (SE). Sedangkan untuk perancangan sistem yang meliputi alur sistem menggunakan diagram Unified Modelling Language (UML).

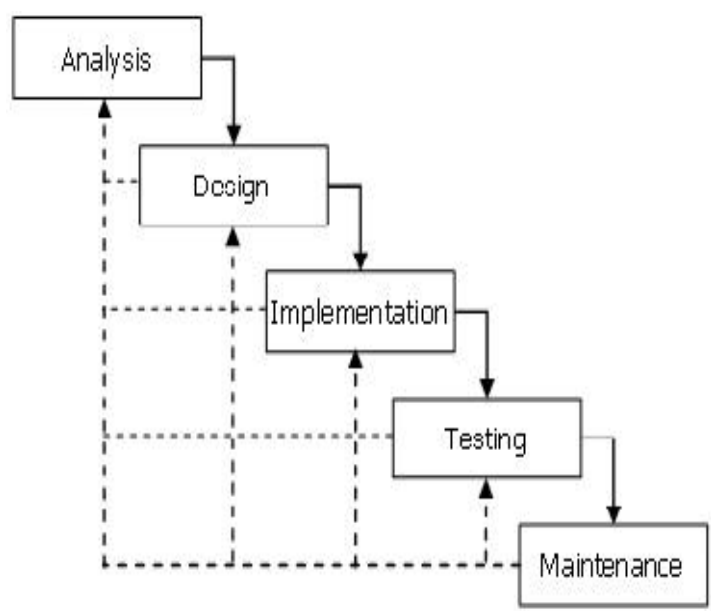

Gambar 1. Tahap Penelitian

\section{Analysis}

Proses pencarian kebutuhan diintensifkan dan difokuskan pada software. Untuk mengetahui sifat dari program yang akan dibuat, maka para software engineer harus mengerti tentang domain informasi dari software, misalnya fungsi yang 
INFORM TIK

Jurnal Informatika, Manajemen dan Komputer, Vol. 13 No.1, Mei 2021

eISSN : 2580-3042

pISSN : 1979-0694

dibutuhkan, user interface, dsb. Dari 2 aktivitas tersebut (pencarian kebutuhan sistem dan software) harus didokumentasikan dan ditunjukkan kepada pengguna. Berdasarkan hasil observasi dan wawancara langsung, peneliti menganalisis bahwa kendalanya adalah terjadinya kesalahan mahasiswa sering menjatuhkan judul yang sudah ada.

2. Design

Proses ini digunakan untuk mengubah kebutuhan-kebutuhan diatas menjadi representasi ke dalam bentuk "blueprint" software sebelum coding dimulai. Desain harus dapat mengimplementasikan kebutuhan yang telah disebutkan pada tahap sebelumnya. Seperti 2 aktivitas sebelumnya, maka proses ini juga harus didokumentasikan sebagai konfigurasi dari software.

Setelah peneliti mendapatkan dokumentasi dari hasil analisis, maka peneliti mengubah kebutuhan-kebutuhan fungsi software diatas menjadi sebuah bentuk "blueprint" software. Sehingga hasil desain akan digunakan oleh peneliti untuk membangun sebuah aplikasi.

3. Implementation

Untuk dapat dimengerti oleh mesin, dalam hal ini adalah komputer, maka desain tadi harus diubah bentuknya menjadi bentuk yang dapat dimengerti oleh mesin, yaitu ke dalam bahasa pemrograman melalui proses coding. Tahap ini merupakan implementasi dari tahap design yang secara teknis nantinya dikerjakan oleh programmer. Pada tahap ini, peneliti membangun sebuah aplikasi berdasarkan desain "blueprint" yang telah dibuat. Pengembangan aplikasi ini dilakukan dari awal hingga aplikasi siap dijalankan. Dari fungsi-fungsi yang dibutuhkan hingga tampilan untuk pengguna (mahasiswa). Penjelasan lebih lengkap dari aktifitas ini terdapat pada lampiran.

4. Testing / Verification

Sesuatu yang dibuat haruslah diujicobakan. Demikian juga dengan software. Semua fungsifungsi software harus diujicobakan, agar software bebas dari error, dan hasilnya harus benar-benar sesuai dengan kebutuhan yang sudah didefinisikan sebelumnya.

5. Maintenance

Pemeliharaan suatu software diperlukan, termasuk di dalamnya adalah pengembangan, karena software yang dibuat tidak selamanya hanya seperti itu. Ketika dijalankan mungkin saja masih ada errors kecil yang tidak ditemukan sebelumnya, atau ada penambahan fitur-fitur yang belum ada pada software tersebut. Pengembangan diperlukan ketika adanya

perubahan dari eksternal perusahaan seperti ketika ada pergantian sistem operasi, atau perangkat lainnya.

\section{HASIL DAN PEMBAHASAN}

\subsection{Analisa Sistem}

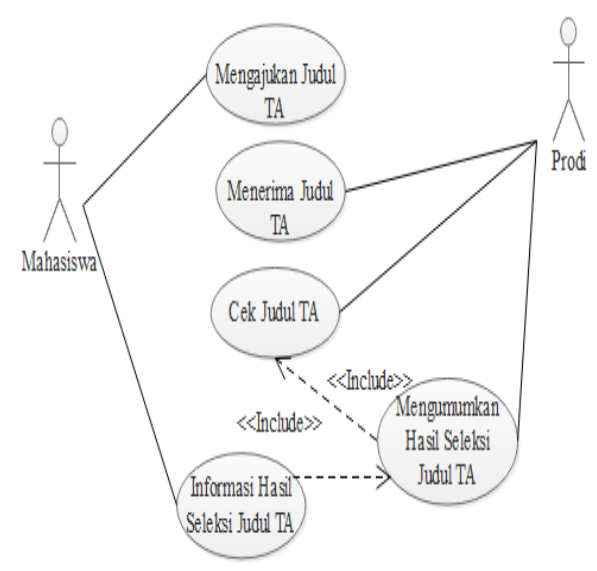

\section{Gambar 2. Usecase Diagram Sedang Berjalan}

Gambar 2 menerangkan bahwa dalam sistem yang sedang berjalan terdapat dua aktor yaitu mahasiswa dan Prodi, dimana mahasiswa mengajukan judul Tugas Akhir melalui Prodi kemudian Prodi menerima judul Tugas Akhir dan menganalisa judul tersebut. Setelah dianalisa judul Tugas Akhir mahasiswa, prodi membuat pengumuman hasil judul Tugas Akhir mahasiswa yang diterima atau ditolak.

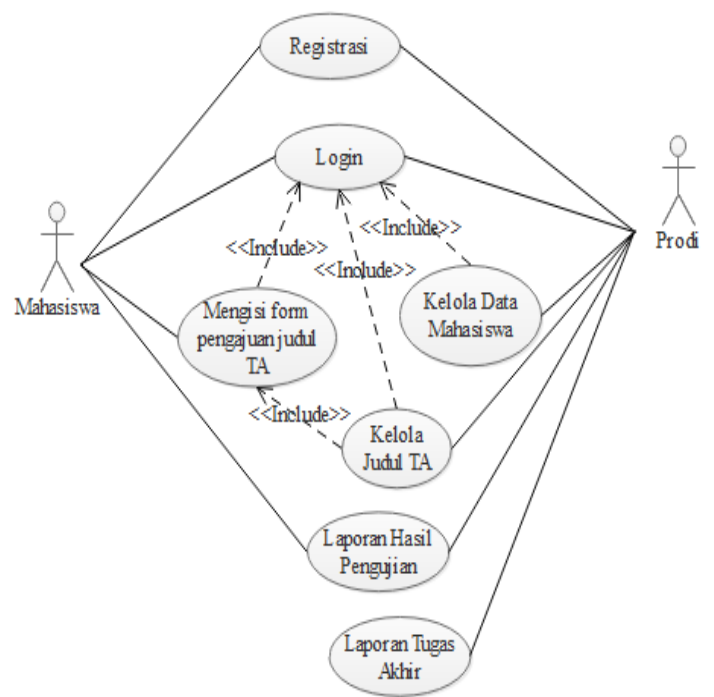

Gambar 3. Usecase Yang Diusulkan

Keterangan gambar 3 menjelaskan bahwa peneliti mengusulkan sistem baru dimana terdapat dua aktor yaitu Mahasiswa dan Prodi. Aktifitas yang dilakukan para aktor adalah login 
INFORM TIK

Jurnal Informatika, Manajemen dan Komputer, Vol. 13 No.1, Mei 2021

eISSN : 2580-3042

pISSN : 1979-0694

terlebih dahulu, kemudian mahasiswa mengisi form pengajuan. Lalu Prodi yang akan mengelola data mahasiswa dan judul Tugas Akhir yang sudah diajukan. Setelah itu mahasiswa dan prodi juga bisa melihat laporan siapa saja mahasiswa yang judulnya diterima atau ditolak, jika diterima berarti tidak ada indikasi plagiat dan jika ditolak maka judul Tugas Akhir tersebut terdapat atau terindikasi plagiatisme.

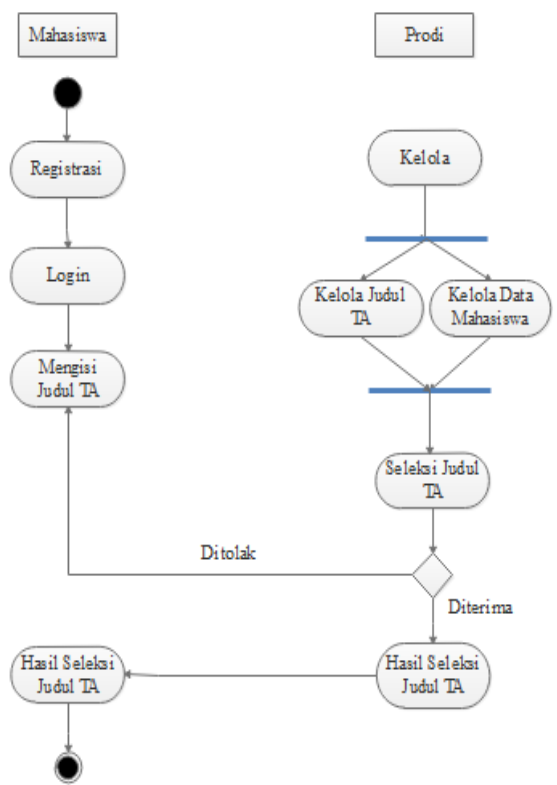

\section{Gambar 4. Activity Diagram Yang Diusulkan}

Pada gambar 4 dijelaskan bahwa aktifitas sistem usulan dimana mahasiswa melakukan login terlebih dahulu setelah itu mengisi form pengajuan judul Tugas Akhir, lalu Prodi akan mengelola data mahasiswa dan mengecek hasil dari pengajuan judul tugas akhir mahasiswa. Kemudian mahasiswa dapat melihat apakah judul Tugas Akhir yang diajukan diterima atau ditolak didalam menu laporan hasil pengajuan judul Tugas Akhir.

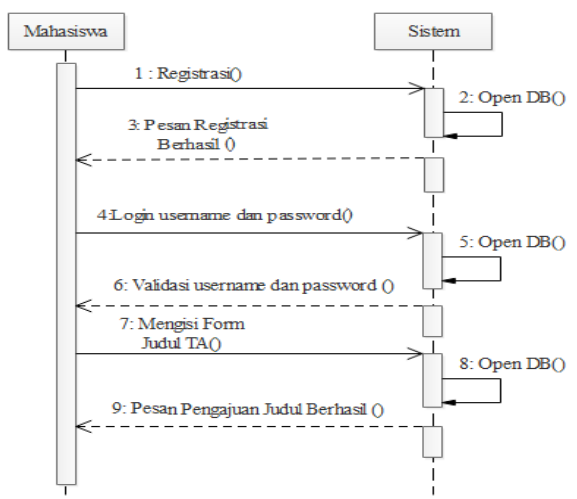

Gambar 5. Squence Diagram Mahasiswa

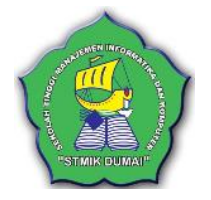

Pada gambar 5 dijelaskan bahwa aktifitas sistem bagi mahasiswa melakukan login terlebih dahulu setelah itu mengisi form pengajuan judul Tugas Akhir, kemudian mahasiswa dapat melihat apakah judul Tugas Akhir yang diajukan diterima atau ditolak didalam menu laporan hasil pengajuan judul Tugas Akhir.

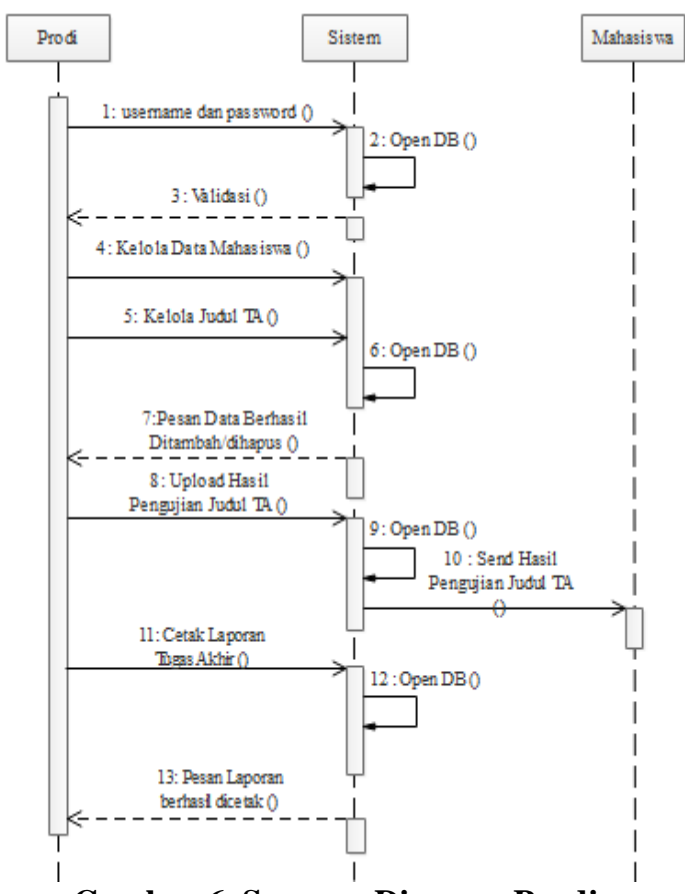

Gambar 6. Squence Diagram Prodi

\subsection{Hasil Pengujian}

Bab ini akan memaparkan hasil implementasi dari perancangan sistem yang sudah dirancang. Berikut ini tampilan- tampilan hasil implementasi dari aplikasi pencagah plagiarisme judul tugas akhir.

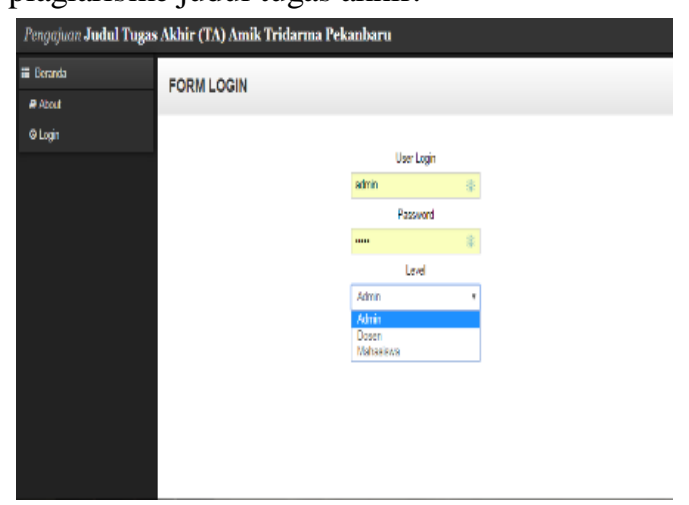

Gambar 7. Tampilan Login

Gambar 7 adalah hasil desain untuk tampilan login bagi mahasiswa dan prodi dalam 
IN F ORM A I I A

Jurnal Informatika, Manajemen dan Komputer, Vol. 13 No.1, Mei 2021

elSSN : 2580-3042

pISSN : 1979-0694

sistem dengan memasukkan username, password dan level.

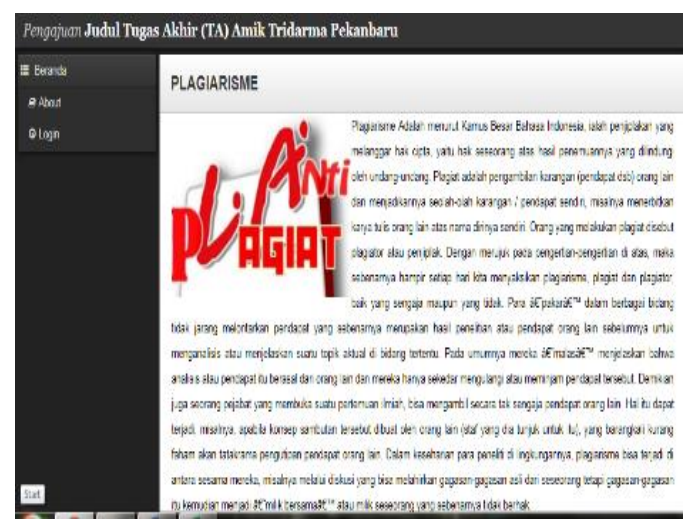

Gambar 8. Tampilan Beranda

Gambar 8 adalah implementasi hasil desain untuk tampilan awal sistem atau beranda pada aplikasi plagiarisme terhadap judul Tugas Akhir Mahasiswa AMIK Tri Dharma Pekanbaru.

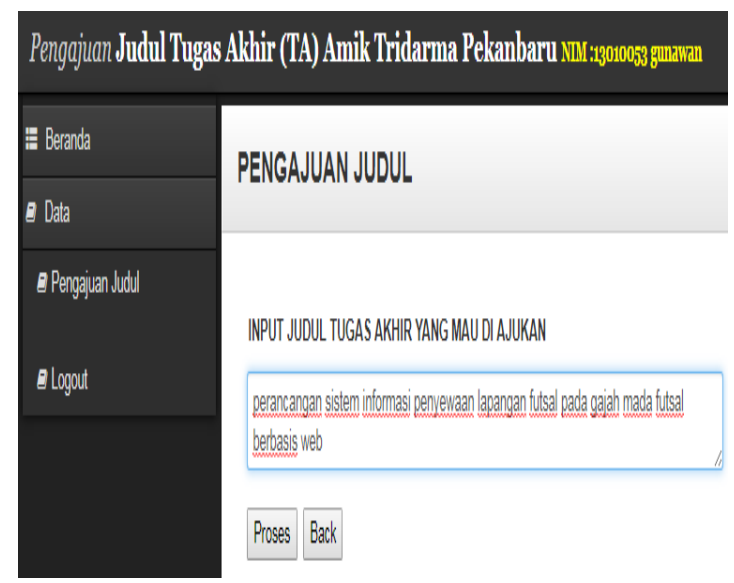

Gambar 9. Tampilan Cek Judul

Gambar 9 implementasi hasil desain form pengajuan judul Tugas Akhir mahasiswa, dimana mahasiswa menginputkan judul yang akan diajukan kemudian simpan pada tombol proses.

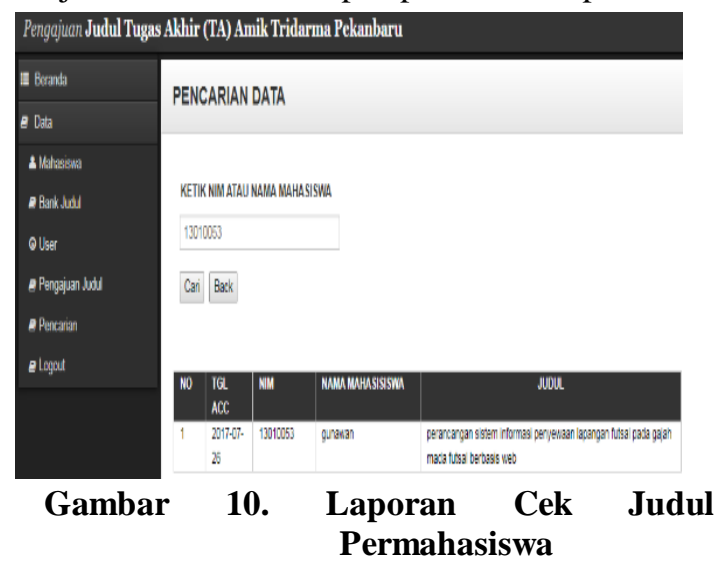

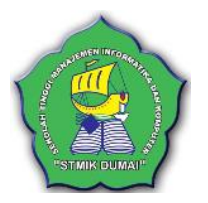

Gambar 10 menunjukkan bahwa Prodi bisa melihat siapa saja yang sudah melakukan pengajuan judul Tugas Akhir dengan menginputkan NIM atau nama mahasiswa.

LAPORAN HASIL PENGUJIAN

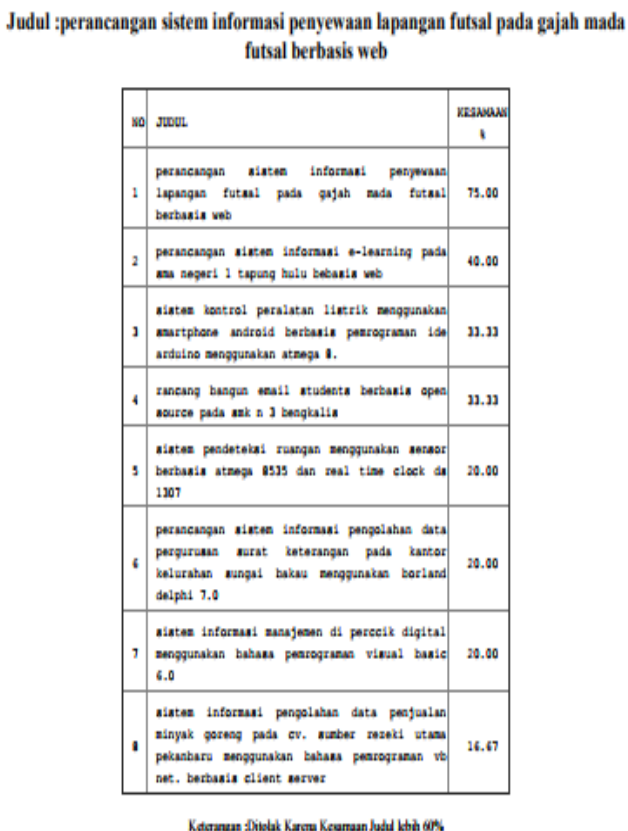

Gambar 11. Laporan Hasil Pengujian

Gambar 11 menunjukkan hasil pengujian terhadap judul Tugas Akhir yang diusulkan oleh mahasiswa apakah terdapat plagiarisme atau tidak.

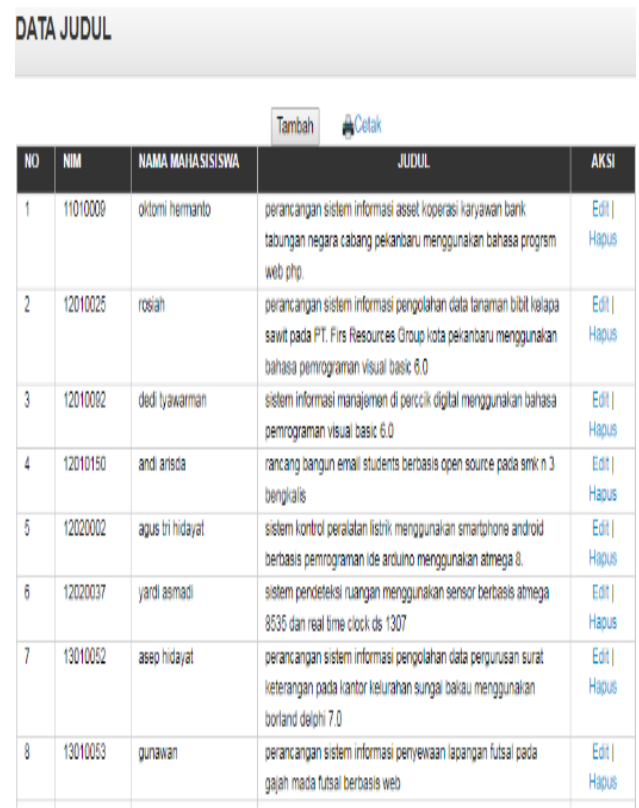

Gambar 12. Laporan Judul Tugas Akhir 
IN F ORM A I I A

Jurnal Informatika, Manajemen dan Komputer, Vol. 13 No.1, Mei 2021

eISSN : 2580-3042

pISSN : 1979-0694

Gambar 12 menunjukkan bahwa baik mahasiswa maupun Prodi bisa melihat hasil dari judul yang sudah diajukan apakah ditolak atau diterima.

\section{KESIMPULAN}

Berdasarkan analisa dan pengujian yang sudah dilakukan maka dapat disimpulkan bahwa pengecekan judul tugas akhir pada Amik Tri Dharma Pekanbaru masih menggunakan pengecekan judul secara manual, sehingga judul yang diajukan sering sekali ditolak oleh dosen dikarenakan judul yang diajukan mahasiswa sama dengan judul yang sudah pernah diajukan oleh mahasiswa terdahulu. Pengecekan judul tugas akhir pada saat ini masih kurang efektif, sehingga mahasiswa lebih akan sulit dalam melakukan pengajuan judul tugas akhir. Hasil pengujian tersebut dibuktikan bahwa aplikasi pencegah plagiasi judul tugas akhir berbasis web yang dibangun dapat berjalan dengan baik dan mempermudah mahasiswa dalam melakukan pengecekan judul tugas akhir.

Diharapakan untuk kedepannnya Amik Tri Dharma Pekanbaru sebaiknya menggunakan aplikasi pencegah plagiasi judul tugas akhir berbasis web, karena dengan menggunakan program tersebut agar dapat mempermudah mahasiswa tiap tahunnya melakukan pengecekan judul tugas akhir dan bisa diakses kapan dan dimanapun.

\section{REFERENSI}

Alief, M. S., Kasih, P., Kom, M., Ayu, M., Widya, D., \& Kom, M. (2018). SISTEM BANTU DETEKSI PLAGIARISME JUDUL SKRIPSI MENGGUNAKAN LATENT SEMANTIC ANALYSIS ( Studi Kasus: Program Studi Akuntansi Universitas Nusantara PGRI Kediri ) Oleh : Dibimbing oleh : SURAT PERNYATAAN ARTIKEL SKRIPSI TAHUN 2018.

Falah, S., Si, M., \& Akuntansi, D. J. (2019). The Community Engagement Journal PELATIHAN MENDELEY DAN ANTIPLAGIAT UNTUK MENINGKATKAN KUALITAS KARYA ILMIAH MAHASISWA, 2(November), 1-5.

Husein, A., \& Alam, S. N. (2018). Pembuatan Sistem Pendeteksi Kemiripan Pengajuan Topic Skripsi Menggunakan Metode Rabin - Karp, 270-274.

Kurniawan, H., \& Bondowoso, W. B. (2019).

Sistem Informasi Terintegrasi Tugas Akhir/Skripsi Berbasis Web (Studi Kasus: Jurusan Sistem Informasi Institut Informatika dan Bisnis Darmajaya). Jurnal Sistem Informasi Dan Manajemen Basis Data (SIMADA), 2(2), 124-134.

M, V. C., Mulyawan, B., Arisandi, D., Studi, P., Informatika, T., \& Informasi, F. T. (2020). IMPLEMENTASI SPELLING CORRECTION DENGAN D-LD DAN RABIN KARP PLAGIARISM CHEKING PADA APLIKASI PENDAFTARAN, 1 , 78-89.

Nurdin, N., Rizal, R., \& Rizwan, R. (2019). Pendeteksian Dokumen Plagiarisme dengan Menggunakan Metode Weight Tree. Telematika, $\quad 12(1), \quad 31$. https://doi.org/10.35671/telematika.v12i1.7 75

Pratama, P., Afriansyah, \& Syaifullah. (2019). PENDETEKSI KESAMAAN DOKUMEN PADA SISTEM INFORMASI PENDAFTARAN PROPOSAL SKRIPSI DENGAN PENDEKATAN ALGORITMA RABIN-KARP. Journal of Information Technology and Computer Science, 2, 39915587.

Pratama, Z., Utami, E., \& Arief, M. R. (2019). Analisa Perbandingan Jenis N-GRAM Dalam Penentuan Similarity Pada Deteksi Plagiat. Creative Information Technology Journal, $4(4), \quad 254$. https://doi.org/10.24076/citec.2017v4i4.11 8

Putra, N. P., \& Sularno. (2019). Penerapan Algoritma Rabin-Karp Dengan Pendekatan Synonym Recognition Sebagai Antisipasi Plagiarisme Pada Penulisan Skripsi. Jurnal Teknologi Dan Sistem Informasi Bisnis, 1(2), 49-58.

Rouf, H. A., Wijayanto, A., \& Aziz, A. (2020). Deteksi Plagiarisme Skripsi Mahasiswa dengan Metode Single-link Clustering dan Jaro-Winkler Distance, 5, 26-31.

Sari, L. P. (2019). Aplikasi Pendeteksi Plagiasi pada Universitas Indo Global Mandiri Berbasis Web, 10(02).

Sibarani, L., Magdalena, M., \& Dharma, A. (2019). Analisa Perbandingan Sistem Pendeteksian Kemiripan Judul Skripsi Menggunakan Algoritma Winnowing Dan Algoritma Rabin Karp. REMIK (Riset Dan E-Jurnal Manajemen Informatika Komputer), $\quad 4(1), \quad 69$. https://doi.org/10.33395/remik.v4i1.10174

Waly, E. (2018). SISTEM INFORMASI 
INFORMA T I K A

Jurnal Informatika, Manajemen dan Komputer, Vol. 13 No.1, Mei 2021

elSSN : 2580-3042

pISSN : 1979-0694

PENCARIAN JUDUL SKRIPSI DAN

TUGAS AKHIR PADA STMIK TIDORE MANDIRI.

Wijayanti, A., \& Hariri. (2019). Persepsi

Mahasiswa Akuntansi Terhadap

Pendeteksian Plagiasi Tugas Akhir, (17), 78-90.

Wulan, F. R. N., Kunaefi, A., \& Permadi, A. (2018). Deteksi Plagiasi Dokumen Skripsi Mahasiswa Menggunakan Metode NGrams Dan Winnowing. Simetris: Jurnal Teknik Mesin, Elektro Dan Ilmu Komputer, 9(2), 1021-1032. https://doi.org/10.24176/simet.v9i2.2535

Yamasari, Y., Asmunin, \& Kurniawan, I. F. (2015). Pengembangan Sistem Informasi Manajemen Skripsi Di Jurusan Teknik Elektro, Ft Unesa. Jurnal Manajemen Informatika, 04(01), 1-10. Retrieved from http://jurnalmahasiswa.unesa.ac.id/index.ph p/jurnal-manajemeninformatika/article/view/11130/4335 